\title{
Front Matter: Volume 10320
}

, "Front Matter: Volume 10320," Proc. SPIE 10320, An Introduction to Biological and Artificial Neural Networks for Pattern Recognition, 1032001 (30 August 2017); doi: 10.1117/12.2284074

SPIE Event: Tutorial Texts in Optical Engineering Series 1991, 1991, Bellingham, WA, United States 


\section{Contents}

$\mathbf{V}$

Lithography equipment: what is out there and what is coming [TTS4-01]

H. J. Levinson, Advanced Micro Devices, Inc.

21 Aspects in the progression of materials and processes for 256-Mb DRAM and beyond [TTS4-02] W. E. Conley, IBM Corp.

58 Processing issues and modeling [TTS4-03]

A. R. Neureuther, Univ. of California/Berkeley

134 Future lithography technology [TTS4-04]

G. E. Fuller, Texas Instruments Inc.

198 Mask technology for 0.25- $\mu \mathrm{m}$ lithography and beyond [TTS4-05]

F. Lo, D. H. Hwang, G. T. Dao, J. N. Farnsworth, W. Rawlins, R. LaVoy, J. DeWitt, R. Goyal,

G. Liu, S. V. Daugherty, Intel Corp. 
Proc. of SPIE Vol. $103201032001-2$

Downloaded From: https://www.spiedigitallibrary.org/conference-proceedings-of-spie on 26 Apr 2023 Terms of Use: https://www.spiedigitallibrary.org/terms-of-use 


\section{Introduction}

This one-day seminar sponsored by Semiconductor Equipment and Materials International (SEMI) and SPIE (The International Society for Optical Engineering) provided detailed information on emerging trends and future directions in tools, materials, and quality control for the microlithography industry.

Attendees at the technology seminar learned competitive and new manufacturing techniques in microlithography from internationally recognized experts. The information presented provided data on implementing new-generation process technology and on lowering manufacturing costs through higher yields.

The material contained in this volume provides attendees with a written reference of the information presented during the oral lectures and is also a valuable standalone reference for those not able to attend the live sessions. 